\title{
The improved unified constitutive model: a fine-tuned material model tailored for more challenging geotechnical conditions
}

\author{
A Vakili Mining One Consultants Pty Ltd, Australia
}

\begin{abstract}
The improved unified constitutive model (IUCM) is a result of collating the most notable recent research works in the area of rock mechanics and extensive back-analysis of mining case histories together into a unified material model. This model has proven to provide a considerably more reliable prediction of rock mass behaviour than currently available modelling methods. Also, a transparent presentation of the model components and a detailed guideline for selection of input parameters make the IUCM an excellent candidate to potentially become a standard material model for numerical modelling in rock mechanics. This model can possibly improve the numerical modelling practices through improved reliability, simplifying application, standardising input selection, simplifying third party reviews and enabling regeneration by third parties.

This paper first discusses the definitions, applications and limitations of conventional modelling methods. A practical and less theoretical introduction to the IUCM is then presented and finally, some case studies are shown where the predictive performance of this model is compared against the most commonly used material models.
\end{abstract}

Keywords: improved unified constitutive modelling (IUCM), advanced numerical modelling, constitutive model, material model

\section{Introduction}

Numerical modelling is increasingly employed in the mining industry to predict the response of the rock mass to various mining activities.

In recent years, increased computational power has facilitated the application of more sophisticated discontinuum models for practical rock mechanics purposes. These models can model the rock response to increasing, or varied, stress levels at a more fundamental level by explicitly representing the discontinuities and the induced fracturing in the rock mass. As a result, these models can replicate complex failure mechanisms much more accurately than a conventional continuum model.

However, owing to computational limitations, these sophisticated discontinuum models are either conducted in 2D or small-scale 3D. Significantly greater computer power is required for construction and analysis of large-scale 3D fully discontinuum models. Furthermore, the input parameters required to construct these models are often not available, nor well understood. Consequently, fewer methods have been developed to derive representative inputs for fully discontinuous models.

In practice, continuum and semi-discontinuum models are quicker to construct and require less computational run time, which has resulted in their wider application amongst practitioners. Consequently, research over the last decade within the field of rock mechanics has mostly focused on methods to define input parameters, refine failure criteria, and develop material models for continuous media.

The main problem associated with continuum models, however, is that they rely heavily on material models. The role of a material model is to implicitly represent the underlying failure mechanisms that are in place without explicitly including the micro-structures, block interactions, or the fracturing process. Therefore, a 
suitable material model is one that can correctly represent the main controlling mechanisms that occur during the process of rock mass loading and failure.

Three types of material models are most commonly used by mining rock mechanics practitioners when conducting a numerical modelling study:

- Linear elastic model.

- Strain-softening-Mohr-Coulomb model (SSMC).

- Proprietary models.

This paper first discusses the definitions, applications and limitation for each of the above models. The Improve Unified Constitutive Model (IUCM) is then briefly described. Finally, three case studies are presented where numerical modelling results from conventional material models are compared to the IUCM outputs.

\section{$2 \quad$ Elastic model}

The linear elastic model assumes that rock behaves elastically under applied loading, meaning that it will return to its initial shape and size when any disturbing forces are removed. In reality, the rock may remain elastic only up to about half to two-thirds of its peak strength. As a result, this model increasingly loses its predictive power as the level of loading and failure increases in the rock mass. This increased loading can be a result of mining at greater depth or a result of mining closer to other large excavations. This model is particularly popular amongst the geotechnical practitioners because of its ease of application.

The applicability of the linear elastic model, however, is still the subject of much debate by professionals. Andrieux et al. (2007) could demonstrate and prove, through worked examples, that in many cases it can be very difficult to correctly interpret the results computed by an elastic approach, particularly when highly stressed mining fronts are involved, and extensive failure occurs. Although some practitioners still trust and prefer the simplistic elastic approaches, it is now widely accepted within the mining community that this approach has a limited range of applicability and, if applied outside its applicable ranges, it can lead to very misleading and potentially dangerous outcomes.

One of the hidden and often less noted risks associated with the elastic approach is the expertise required for interpretation of the results. This is because the interpretation of elastic models is often made indirectly, and model outputs such as displacement, strain and velocity cannot be used directly for interpretation.

Elastic models require only few input parameters, and there's often a standard and easy guideline for selection of these inputs. However, it is often overlooked by the practitioners that additional input parameters are needed when interpreting the results of these elastic models. This often means that uncertainties associated with the initial input data will be equally reflected in both elastic and inelastic model results, but one in the immediate model output and the other one through interpretation of results.

Despite all the debates in the mining industry regarding the usefulness of the elastic models, the primary reason for the popularity of these models is their ease of application and lesser expertise required for selection of its input parameters.

The elastic approach can provide results that are comparable to more sophisticated inelastic models in less complex ground conditions, however, in more complex conditions these models should not be relied upon. This limitation of the elastic models should, under no circumstances, be ignored even when sufficient input parameters are non-existent.

\section{Strain-softening-Mohr-Coulomb model}

The Mohr-Coulomb peak strength criterion and associated constitutive models have gained wide acceptance and application in the field of geotechnical engineering. Many analysis methods and software programs still use this criterion as part of their default constitutive model. This criterion is obtained from two key 
parameters-cohesion $(c)$ and friction angle $(\phi)$, which became widely accepted parameters for describing soil and rock strength properties.

According to Brown (2008), the linear Mohr-Coulomb consisting of two independent cohesive and frictional components does not provide a realistic representation of the progressive failure and disintegration of rock under stress. Some recent studies, such as Hajiabdolmajid et al. (2002), Barton and Pandey (2011), and Barton (2013), also highlighted the limitations of this model and its application in predicting damage in rock material.

Because most modelling software codes (and also the majority of practitioners) still use the Mohr-Coulomb failure criterion, a line-fitting procedure was proposed to find equivalent cohesion and friction angle values based on the Hoek-Brown curves and the maximum confinement pressures. Nonetheless, there remain two fundamental problems associated with applying a linear model which often lead to a considerable mismatch between the Hoek-Brown and the Mohr-Coulomb predicted peak stress values. The first problem is that in many rock mechanics applications, such as mining, a significant variation exists in the level of confinement at different locations within the rock mass. Secondly, even for a particular excavation at a given depth, there can be a considerable variation in confinement levels depending on the position with respect to the excavation boundaries. This is mainly caused by the redistribution of stress around excavations and also new phases of confinement that can be induced as a result of nearby excavations or yielded material. These two issues can be more pronounced in high stress and high yield environments, or in rock material that exhibits a more curved peak failure envelope (rocks with high Hoek-Brown material constant $m$ values).

More advanced numerical modelling users often couple the Mohr-Coulomb failure criterion with a strain-softening post-peak to model the full stress-strain behaviour of the rock mass. In this paper, this approach is referred to as Strain-Softening-Mohr-Coulomb (SSMC) model.

Another problem associated with the SSMC model is the lack of a consistent guideline for selection of input parameters. The parameters such as cohesion, tensile strength and friction angle are often assigned through line-fitting to the Hoek-Brown curves. However, there is no standard procedure for assigning the post-peak parameters, and therefore considerable differences can exist between values chosen by various practitioners. Also, the inputs of this model (cohesion, friction angle, etc.) cannot easily be compared with parameters collected from the field (such as UCS, GSI, etc.).

\section{$4 \quad$ Proprietary models}

The third category of material models are those used by specialist numerical modelling consultants. These models include proprietary algorithms and processes that are used by those consultants to solve the full stress-strain behaviour within the numerical models. Although the owners heavily promote the capability and accuracy of these models, several fundamental issues arise from them. Some of these problems include:

- Lack of transparency regarding the technical details, theories, background and limitations of these methods. The proprietors often relate this ambiguity to proprietary and commercially sensitive nature of these methods.

- Third party review of the modelling studies completed using these methods is often limited to reviewing the selection of input parameters and the interpretation of the results. The most important component of these studies (the modelling method and material models), which largely control the reliability of the outcome, cannot be reviewed. This is particularly a major concern when the result of these modelling studies are used to make decisions for multimillion dollar mining projects.

- Because these methods are not commercially or publicly available, modelling results generated through these methods cannot be reproduced by third parties.

\section{$5 \quad$ The IUCM material model}

The IUCM was developed with the intention to address the limitations of the current modelling practices described earlier in this paper. 
This model gathers the most notable and widely accepted previous research work in the area of rock mechanics and integrates it into a unified constitutive model that can better and more accurately predict the stress-strain relationships in a continuum model. Several back-analyses and validation studies completed during the development of this model confirmed its applicability for a broad range of ground conditions, from massive brittle hard rock to heavily jointed and ductile rock, and also anisotropic rock.

In developing this model, the use of any new theory or technique was avoided where possible, and all the adopted processes were based on well-accepted and widely applied rock mechanics techniques and theories.

The IUCM accounts for significant and fundamental mechanisms, such as the transition from brittle to ductile response, confinement-dependent strain-softening, dilatational response, strength anisotropy, and stiffness softening. The IUCM was developed with the intention to provide a unified material model that has the complexities required for application to a wide range of geotechnical applications and conditions, yet is simple enough to be used by most geotechnical practitioners.

The key components and features of the IUCM are:

- For the peak failure envelope of the rock matrix, the IUCM uses the generalised Hoek-Brown failure criterion (for the intact rock if the GSI is 100 and for the rock massif GSI is less than 100) to determine the instantaneous Mohr-Coulomb parameters ( $c$ and $\phi$ ) at each level of confining stress ( $\pm 0.001 \mathrm{MPa}$ tolerance). These instantaneous parameters are updated in real-time as the model runs and as new phases of confinement are formed from nearby damage or geometrical changes.

- For the residual state of the rock matrix, the IUCM assigns a linear Mohr-Coulomb envelope. Properties of completely broken and crushed rock are applied by default for the residual state of the material using cohesion and tensile strength values of 0 , and a friction angle of $45^{\circ}$.

- The critical strain in this model is chosen based on equations suggested by Lorig and Varona (2013). In this method, critical strain values are determined based on model zone size and the GSI value of each rock unit.

- The dilation angle in this model is determined using the relationship proposed by Alejano and Alonso (2005). This relationship gives an estimate of the peak dilation angle based on confinement, friction angle, and UCS. The dependency of this relationship on confinement levels results in higher dilation angles at lower confinements, and lower dilation angles at higher confinements. Additionally, it causes a degradation of dilation angle with increasing damage, and ultimately the dilation angle is reduced to zero when the maximum porosity of $40 \%$ is reached in the model zones. This behaviour is similar to that observed in laboratory rock testing results.

- The IUCM accounts for the confinement dependency of the rock damage process at various stages from peak to residual. Confinement dependency is an important factor controlling rock damage and seismicity in high stress conditions; however, it is largely ignored in most conventional constitutive models. In the IUCM, at low confinement levels, the linear nature of the residual envelope replicates cohesion and friction softening. At high confinement levels, it replicates cohesion softening and friction hardening.

- Most conventional constitutive models assume a constant modulus of elasticity for the rock mass, irrespective of its damage state. In real-life situations, when rock undergoes failure and continuous loading, more voids are generated within the rock mass. The rock mass porosity is subsequently increased. The greater the porosity in the rock mass, the lower its elastic modulus. The drop in rock mass modulus can significantly affect the redistribution of stresses around a failed area and the subsequent phases of induced confinement. The IUCM uses a relationship to update the elastic modulus values according to new porosity levels. The porosity is calculated using the model volumetric strain outputs. 
- The strength anisotropy in the IUCM is explicitly included through a ubiquitous joint model, which accounts for both rock matrix strength and the lower strength associated with the existence of an anisotropy plane. For anisotropic rocks, the model uses two non-linear Hoek-Brown failure envelopes. One envelope defines the maximum strength and is related to the rock matrix strength. The other defines the minimum strength associated with the anisotropy plane.

- This constitutive model is implemented in the explicit finite difference code FLAC3D (currently for version 5.0) and in 3DEC (currently for version 5.0) and therefore uses a time-stepping solution for calculations. As a result, progressive and time-dependent failures can be replicated in this model by updating the material properties as a function of new confinement and strain levels.

General benefits of the IUCM are:

- A detailed and transparent description of all the model's components are presented by Vakili (2016). This includes step by step instructions on the procedures that were implemented in each of the model's algorithms.

- The model has been extensively validated using several well-documented and well-known mining case histories.

- A detailed guideline for selection of input parameters is provided by Vakili (2016).

- A full description of the current known limitations of the model is provided (Vakili 2016).

- The IUCM can result in considerably more reliable modelling outcomes in more complex ground conditions.

- The IUCM only requires four input parameters for isotropic rocks and three additional input for anisotropic rocks. All these inputs can be obtained from conventional laboratory testing and rock mass characterisation, which are often available in most mining projects.

- Application of the IUCM requires much less expertise than other inelastic models.

More specific benefits of the IUCM for more advanced users are:

- IUCM considerably reduces the time to prepare the model input files.

- There is no requirement for establishing strain-softening tables when using the IUCM.

- The critical strain is calculated for each finite difference zone (or mesh element) separately based on its GSI and the zone size.

- Full multi-linear fit to Hoek-Brown with an accuracy of $0.001 \mathrm{MPa}$ is used, instead of a linear or a bilinear fit.

- A Hoek-Brown envelope is used for the ubiquitous joint as well as the matrix.

- The following sections outline the details of three case studies where reliability of the IUCM model predictions is compared to elastic and SSMC.

\section{Back-analysis of observed damage in a massive brittle rock mass}

The Mine-by-Experiment project completed by Atomic Energy of Canada Ltd. (AECL) has been the subject of several research efforts attempting to understand the failure mechanism of massive brittle rock masses better. A test tunnel $46 \mathrm{~m}$ long and $3.5 \mathrm{~m}$ in diameter, excavated as part of this project, was used most frequently in the various studies. Read (1994) and Martin (1997) documented more details about the project. Works conducted by Martin (1997), Martin et al. (1999), Diederichs (1999), Diederichs et al. (2004), and Hajiabdolmajid et al. (2002) demonstrated the limitations and errors associated with the application of conventional analysis techniques and constitutive models in predicting the complex mechanisms involved in the brittle intact rock failure. These works proposed alternative approaches including the cohesion 
weakening and frictional strengthening (CWFS) and they showed that the alternative models were able to reproduce the observed failure mechanism more accurately.

It was well documented that the brittle damage and the resulting V-shaped notches evolved gradually in a progressive and time-dependent manner. In this type of failure, the initial yield within the rock mass gradually initiates new phases of confinement, and therefore, new phases of yield and failure can also be initiated.

The Mine-by-Experiment tunnel case was used as a case example to validate the IUCM for predicting the failure mechanism in a massive brittle rock mass. The elastic and the SSMC model results were also used for comparison. The input parameters were adopted according to reported data by Read (1994) and Martin (1997). For the IUCM model, guidelines provided by Vakili (2016) were used to derive the inputs. Full list of input parameters used in each model is listed in Table 1.

Table 1 Input parameters used for the back-analysis of observed damage in a massive brittle rock mass

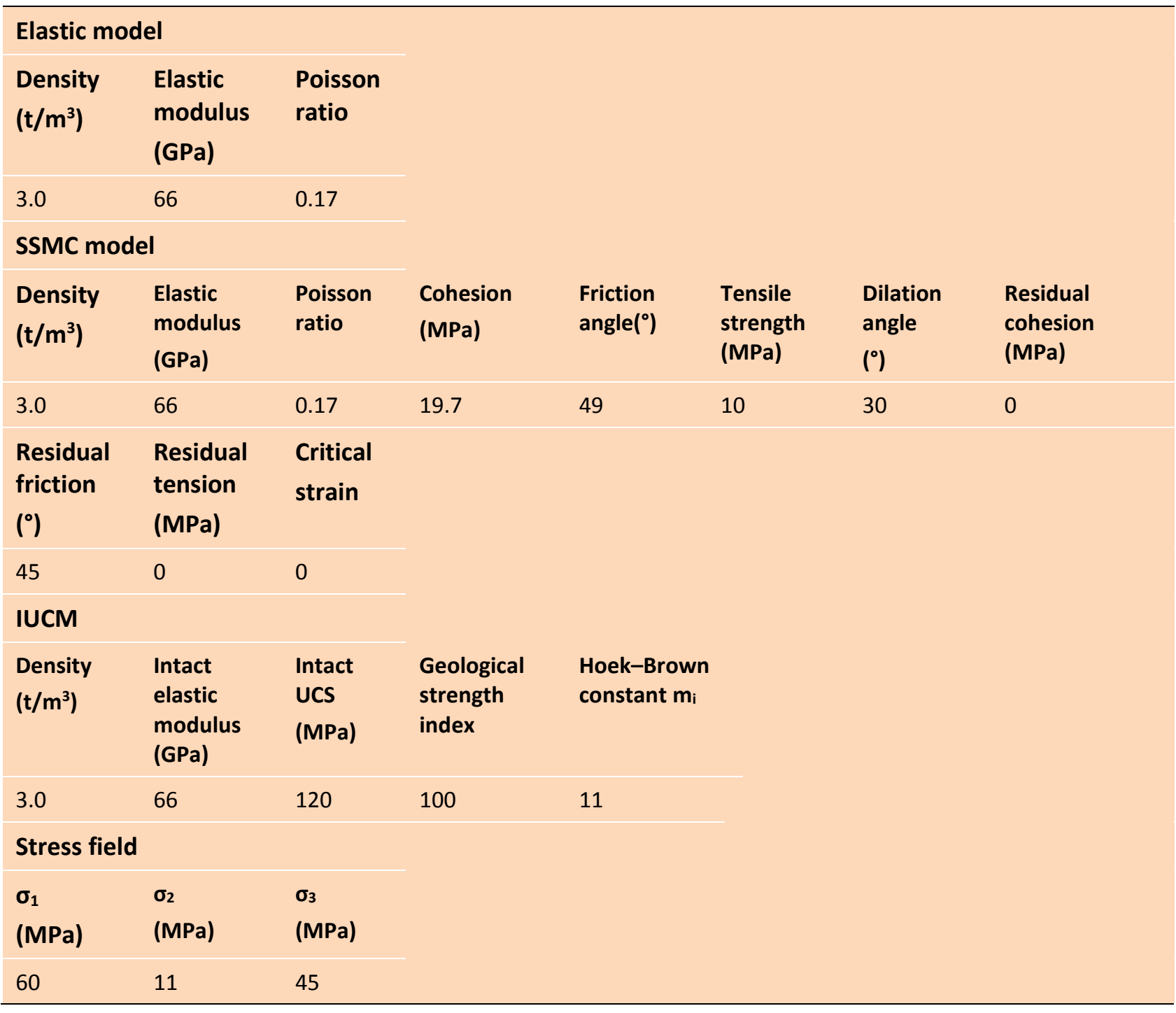

Figure 1 shows a comparison between the three models. For each case, model velocity, volumetric strain and differential stresses are plotted. For the elastic model, direct indicators like velocity and strain could not be used for model interpretation, and results are often interpreted indirectly through stress outputs. However, in inelastic models (SSMC and IUCM in this case), the direct indicators can be used. 


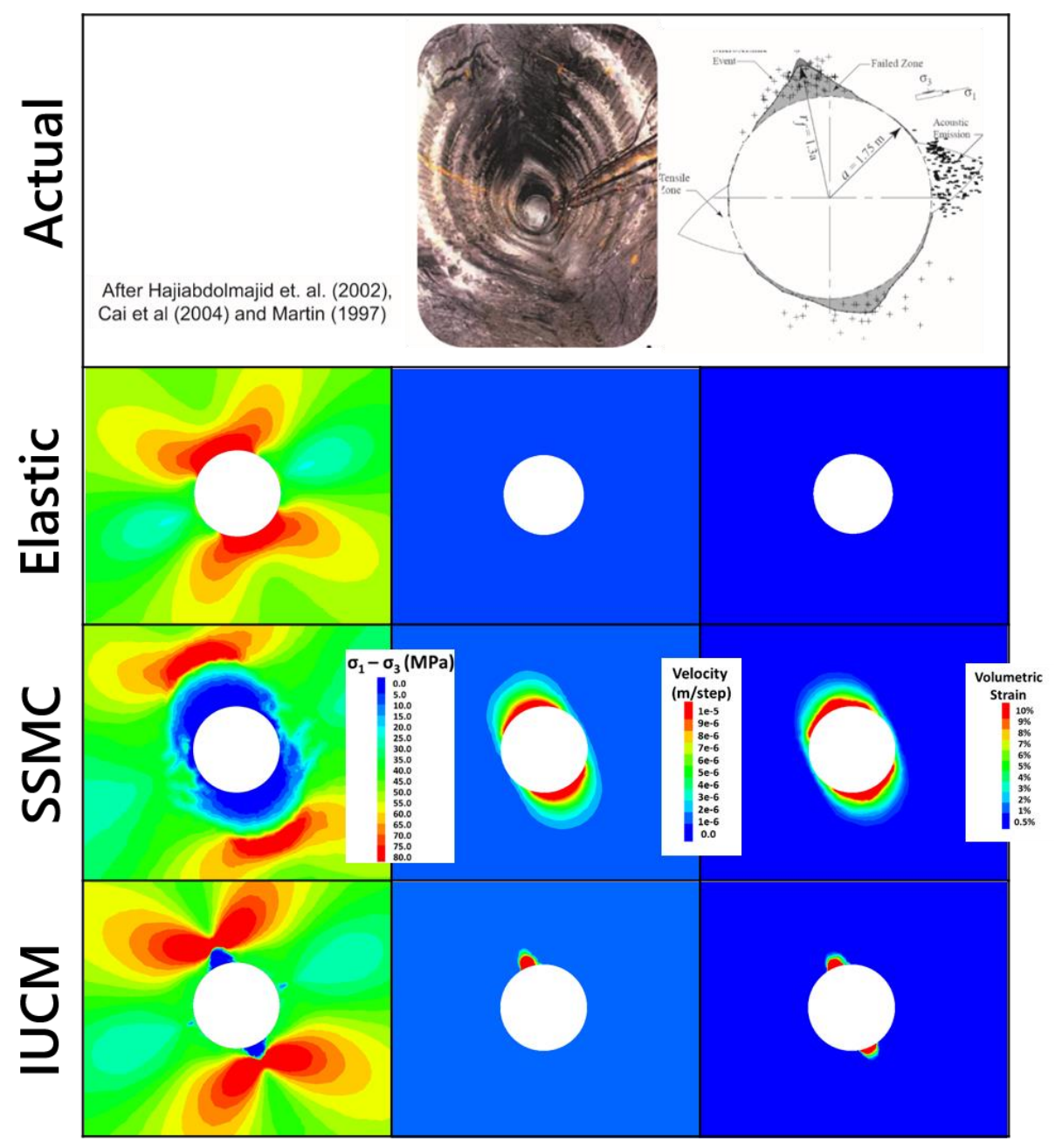

Figure 1 Back-analysis of observed damage in a massive brittle rock mass

As shown in Figure 1, the elastic model could not predict the observed V-shaped notches. This model also over-predicts the extent of damage at the roof and floor positions and shows no signs of de-stressing in the side walls.

The SSMC model, over predicts the extent, severity and mechanism of damage both on the side walls and in roof and floor.

The IUCM model was able to predict the extent, severity and shape of the observed damage around the opening accurately.

\section{Back-analysis of observed damage in an anisotropic, highly jointed, and ductile rock mass}

The complex buckling type failure mechanism associated with a vertical shaft was the subject of another case study, which was rigorously investigated throughout the development of the IUCM. The subject shaft was excavated using a raise-boring technique at an approximate underground depth of $1,500 \mathrm{~m}$. The rock mass at the site was highly foliated and anisotropic with a high degree of jointing.

As reported by Vakili et al. (2012) and Vakili et al. (2014), shortly after excavation, significant buckling was observed in the east and west walls of the shaft with around $1 \mathrm{~m}$ of the initial breakout. Ultimately, after approximately six months of shaft excavation, the east and west walls experienced up to $2.5 \mathrm{~m}$ of breakout with a final ellipse-like shape. 
The input parameters (Table 2) used were mostly derived from geotechnical logging data, structural mapping and laboratory testing with some minor adjustments to obtain a better match with the observations for the IUCM model.

Table 2 Input parameters used for the back-analysis of observed damage in an anisotropic, highly jointed, and ductile rock mass

\begin{tabular}{|c|c|c|c|c|c|c|c|}
\hline \multicolumn{8}{|c|}{ Elastic model } \\
\hline $\begin{array}{l}\text { Density } \\
\left(t / \mathrm{m}^{3}\right)\end{array}$ & $\begin{array}{l}\text { Elastic } \\
\text { modulus } \\
(\mathrm{GPa})\end{array}$ & $\begin{array}{l}\text { Poisson } \\
\text { ratio }\end{array}$ & & & & & \\
\hline 2.8 & 11 & 0.25 & & & & & \\
\hline \multicolumn{8}{|c|}{ SSMC model } \\
\hline $\begin{array}{l}\text { Density } \\
\left(\mathrm{t} / \mathrm{m}^{3}\right)\end{array}$ & $\begin{array}{l}\text { Elastic } \\
\text { modulus } \\
\text { (GPa) }\end{array}$ & $\begin{array}{l}\text { Poisson } \\
\text { ratio }\end{array}$ & $\begin{array}{l}\text { Cohesion } \\
\text { (MPa) }\end{array}$ & $\begin{array}{l}\text { Friction } \\
\text { angle } \\
\left(^{\circ}\right)\end{array}$ & $\begin{array}{l}\text { Tensile } \\
\text { strength } \\
\text { (MPa) }\end{array}$ & $\begin{array}{l}\text { Dilation } \\
\text { angle } \\
\left(^{\circ}\right)\end{array}$ & $\begin{array}{l}\text { Residual } \\
\text { cohesion } \\
(\mathrm{MPa})\end{array}$ \\
\hline 2.8 & 11 & 0.25 & 3.4 & 30 & 0.02 & 10 & 0 \\
\hline $\begin{array}{l}\text { Residual } \\
\text { friction } \\
\left({ }^{\circ}\right)\end{array}$ & $\begin{array}{l}\text { Residual } \\
\text { tension } \\
\text { (MPa) }\end{array}$ & $\begin{array}{l}\text { Critical } \\
\text { strain }\end{array}$ & & & & & \\
\hline 45 & 0 & 0.056 & & & & & \\
\hline \multicolumn{8}{|c|}{ IUCM model } \\
\hline $\begin{array}{l}\text { Density } \\
\left(t / m^{3}\right)\end{array}$ & $\begin{array}{l}\text { Intact } \\
\text { elastic } \\
\text { modulus } \\
\text { (GPa) }\end{array}$ & $\begin{array}{l}\text { Intact UCS } \\
\text { (MPa) }\end{array}$ & $\begin{array}{l}\text { Geological } \\
\text { strength } \\
\text { index }\end{array}$ & $\begin{array}{l}\text { Hoek-Brown } \\
\text { constant } m_{i}\end{array}$ & $\begin{array}{l}\text { Anisotropy } \\
\text { factor }\end{array}$ & $\begin{array}{l}\text { Hoek-Brown } \\
\text { constant } m_{i} \\
\text { for plane of } \\
\text { anisotropy }\end{array}$ & $\begin{array}{l}\text { Anisotropy } \\
\text { orientation } \\
\left(^{\circ}\right)\end{array}$ \\
\hline 2.8 & 50 & 185 & 55 & 30 & 10 & 15 & $\begin{array}{l}\text { Dip: } 85 \\
\text { DipD: } 270\end{array}$ \\
\hline \multicolumn{8}{|c|}{ Stress Field } \\
\hline $\begin{array}{l}\sigma_{1} \\
(\mathrm{MPa})\end{array}$ & $\begin{array}{l}\sigma_{2} \\
(\mathrm{MPa})\end{array}$ & $\begin{array}{l}\sigma_{3} \\
(\mathrm{MPa})\end{array}$ & & & & & \\
\hline 66 & 44 & 38 & & & & & \\
\hline
\end{tabular}

As shown in Figure 2, the elastic and SSMC models could not capture the mechanism, location and extent of the buckling mechanism. Both models suggest that maximum movement and damage should be expected on the north and south wall, unlike the actual observation where the buckling failure took place on the east and west walls. In fact, no signs of movement or cracking were present on the north and south walls. 


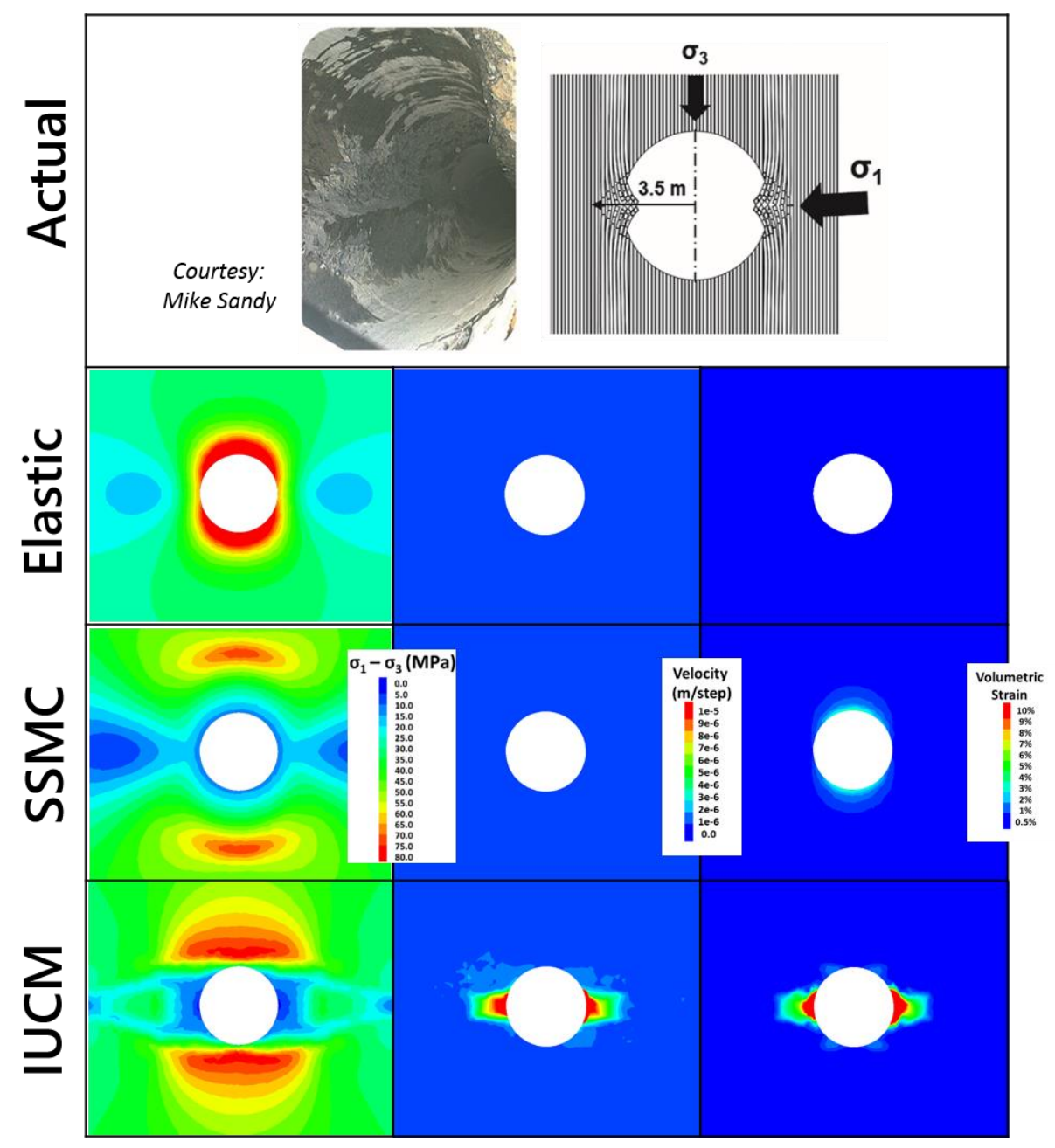

Figure 2 Back-analysis of observed damage in an anisotropic, highly jointed, and ductile rock mass

The IUCM model was able to accurately predict the mechanism, location and extent of the observed damage buckling mechanism.

The IUCM, using similar input parameters, was also used at this site to back-analyse the response of the rock mass in a development drive that was carefully monitored using extensometers. As shown by Vakili et al. (2014), a good correlation was also observed between model and actual observations regarding location of the failure, mechanism of failure, depth of failure, and monitored displacement.

\section{Back-analysis of observed damage in a deep underground open stope}

The rock mass damage observed in the hanging wall of an underground open stope excavation was also used to validate the IUCM and compare its accuracy with conventional models. Details regarding this case study were also presented by Vakili et al. 2014. The subject excavation was found to be a good case for validation of the IUCM for the following reasons:

- The subject stope was excavated in a relatively isolated location from other mining excavations, ensuring that no mining induced stresses affected the observed failure mechanism.

- The observed failure was mainly stress-induced, and no major influence from the local structures was evident.

- The ground condition under study was high stress and involved both massive brittle hard rock and strength anisotropy associated with the foliated fabric in the rock mass. The combination of all 
these factors led to high complexity associated with this rock mass, which makes it a good case for validation studies.

The majority of the applied input parameters were within the ranges obtained from laboratory testing, underground mapping, and geotechnical logging. Only minor adjustments were made to obtain a better match with the observations. These adjustments, and more detailed descriptions about this case, are outlined by Vakili et al. 2014. The input parameters used in each model is listed in Table 3.

Table 3 Input parameters for the back-analysis of observed damage in a deep underground open stope

\begin{tabular}{|c|c|c|c|c|c|c|c|}
\hline \multicolumn{8}{|c|}{ Elastic model } \\
\hline $\begin{array}{l}\text { Density } \\
\left(t / \mathrm{m}^{3}\right)\end{array}$ & $\begin{array}{l}\text { Elastic } \\
\text { modulus } \\
(\mathrm{GPa})\end{array}$ & $\begin{array}{l}\text { Poisson } \\
\text { ratio }\end{array}$ & & & & & \\
\hline 2.8 & 23.4 & 0.23 & & & & & \\
\hline \multicolumn{8}{|c|}{ SSMC model } \\
\hline $\begin{array}{l}\text { Density } \\
\left(t / \mathrm{m}^{3}\right)\end{array}$ & $\begin{array}{l}\text { Elastic } \\
\text { modulus } \\
\text { (GPa) }\end{array}$ & $\begin{array}{l}\text { Poisson } \\
\text { ratio }\end{array}$ & $\begin{array}{l}\text { Cohesion } \\
\text { (MPa) }\end{array}$ & $\begin{array}{l}\text { Friction } \\
\text { angle } \\
\left({ }^{\circ}\right)\end{array}$ & $\begin{array}{l}\text { Tensile } \\
\text { strength } \\
\text { (MPa) }\end{array}$ & $\begin{array}{l}\text { Dilation } \\
\text { angle } \\
\left({ }^{\circ}\right)\end{array}$ & $\begin{array}{l}\text { Residual } \\
\text { cohesion } \\
(\mathrm{MPa})\end{array}$ \\
\hline 2.8 & 23.4 & 0.23 & 5.5 & 44 & 0.375 & 13 & 0 \\
\hline $\begin{array}{l}\text { Residual } \\
\text { friction } \\
\left({ }^{\circ}\right)\end{array}$ & $\begin{array}{l}\text { Residual } \\
\text { tension } \\
\text { (MPa) }\end{array}$ & $\begin{array}{l}\text { Critical } \\
\text { strain }\end{array}$ & & & & & \\
\hline 45 & 0 & 0.18 & & & & & \\
\hline \multicolumn{8}{|l|}{ IUCM } \\
\hline $\begin{array}{l}\text { Density } \\
\left(t / \mathrm{m}^{3}\right)\end{array}$ & $\begin{array}{l}\text { Intact } \\
\text { elastic } \\
\text { modulus } \\
(\mathrm{GPa})\end{array}$ & $\begin{array}{l}\text { Intact UCS } \\
\text { (MPa) }\end{array}$ & $\begin{array}{l}\text { Geological } \\
\text { strength } \\
\text { index }\end{array}$ & $\begin{array}{l}\text { Hoek-Brown } \\
\text { Constant mi }\end{array}$ & $\begin{array}{l}\text { Anisotropy } \\
\text { factor }\end{array}$ & $\begin{array}{l}\text { Hoek-Brown } \\
\text { Constant mi } \\
\text { for plane of } \\
\text { anisotropy }\end{array}$ & $\begin{array}{l}\text { Anisotropy } \\
\text { orientation } \\
\left({ }^{\circ}\right)\end{array}$ \\
\hline 2.8 & 45 & 130 & 60 & 17 & 4 & 8.5 & $\begin{array}{l}\text { Dip: } 46 \\
\text { DipD: } 77\end{array}$ \\
\hline \multicolumn{8}{|c|}{ Stress field } \\
\hline $\begin{array}{l}\sigma_{1} \\
(\mathrm{MPa})\end{array}$ & $\begin{array}{l}\sigma_{2} \\
(\mathrm{MPa})\end{array}$ & $\begin{array}{l}\sigma_{3} \\
(\mathrm{MPa})\end{array}$ & & & & & \\
\hline 70 & 58 & 33 & & & & & \\
\hline
\end{tabular}

The mining depth was approximately $1,500 \mathrm{~m}$ and the stope was excavated by blasting in three separate firings. No major failure was observed until the final firing took place. Significant hanging wall overbreak (to a depth of up to $17 \mathrm{~m}$ ) was recorded. The stoping on both sides of this particular stope continued, and the conditions of the hanging wall of the subsequent stopes were monitored as well.

Both inelastic models (IUCM and SSMC) incorporated the backfill following the excavation of the initial stope but no backfill was included in the elastic model (to replicate the worst case hanging wall condition in this model). 
Figure 3 shows the comparison of model outputs for a single stope and Figure 4 demonstrates the comparison of results for the case when all stopes in the level were completed. It is important to note that the information collected from the stope Cavity Monitoring Systems (CMS) surveys reflects the conditions of the stope following its excavation while the model outputs shown here show the conditions of the hanging wall at the completion of all stopes on the mining level. It is for this reason that velocity plots were not included here, because backfilled stopes would show no velocity in their hanging wall and it is only the volumetric strain that can provide an indication of historical damage that occurred during the previous mining steps.

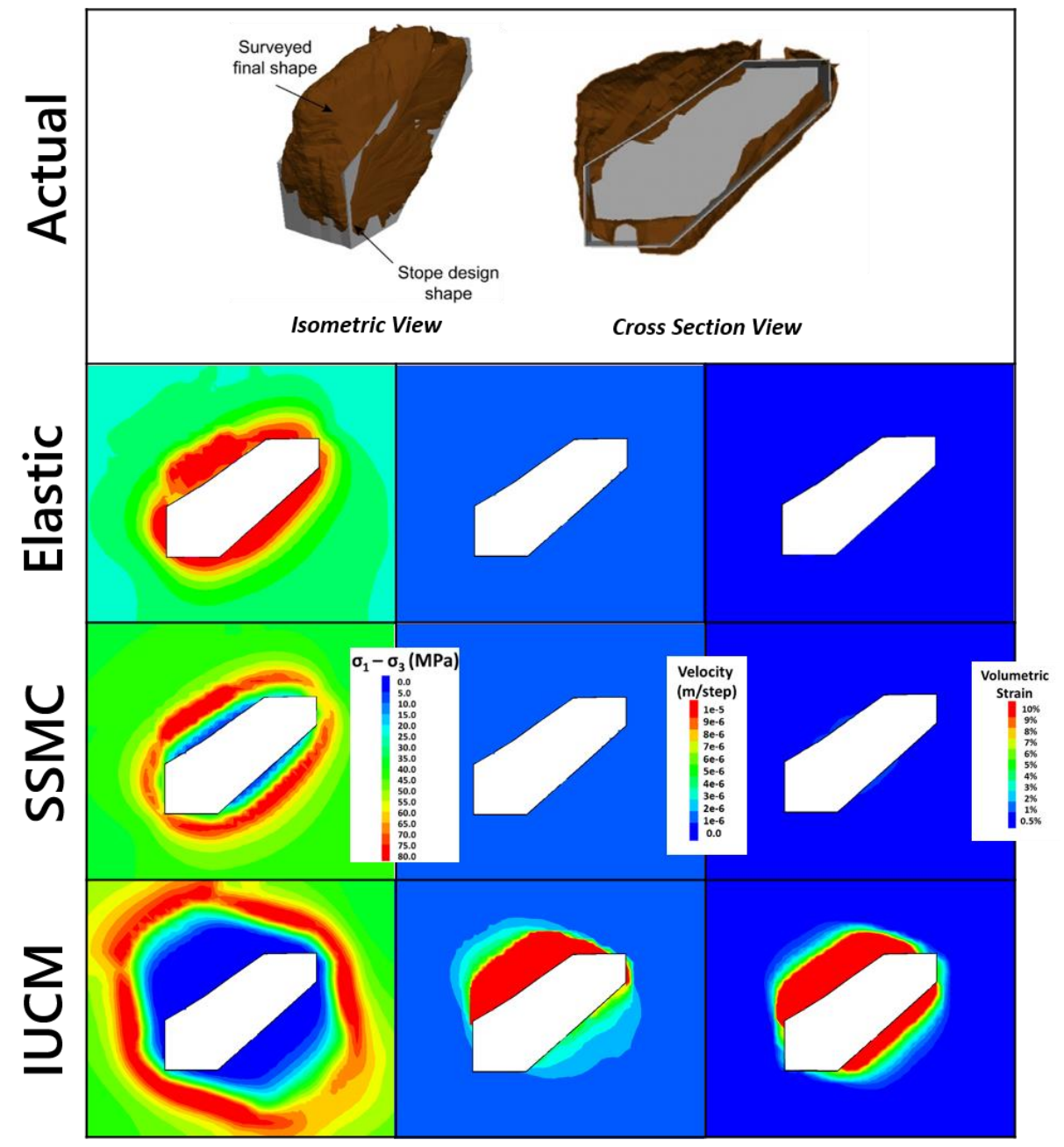

Figure 3 Back-analysis of observed damage in a deep underground open stope (initial stope) 


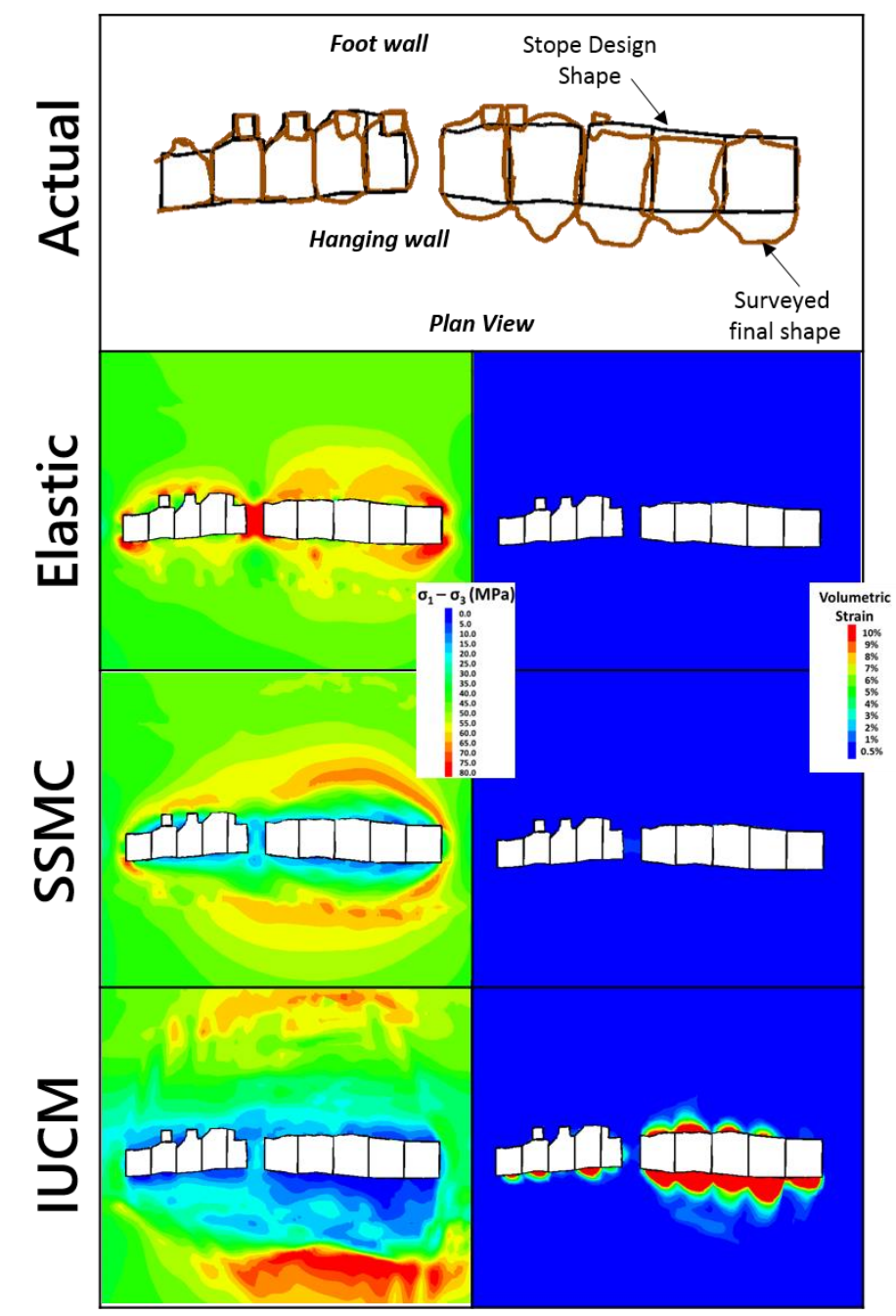

Figure 4 Back-analysis of observed damage in a deep underground open stope (complete stope excavation on the level)

When reviewing the results shown in Figure 3, one can conclude that the elastic model could provide an acceptable estimate of the hanging wall conditions after excavation of the initial stope. This would naturally lead to a conclusion that this model can also forecast the condition for future mining. However as shown in Figure 4, once subsequent stopes on both sides are excavated, the elastic model provided an entirely wrong prediction of the future conditions.

After excavation of the initial stope, the elastic model broadly predicts the damage in the hanging wall with underestimation of the expected damage. However, this model also suggests considerable damage in the sidewalls and footwall which does not correlate with the observations. The SSMC model considerably underestimate the damage in the hanging wall and suggests just some minor de-stressing the hanging wall. The IUCM model provides the most accurate estimate of damage in the hanging wall, foot wall and the sidewalls.

After completion of stope excavation on the level, the discrepancies between the model outputs and actual observations increase considerably. The elastic model shows minor issues in the stope hanging walls and instead considerable damage in the rib pillar left between stope on this level, suggesting that this pillar must have been completely collapsed in real life, which was not the case. The SSMC model also shows signs that the damage in the pillar must have been greater than damage in the hanging wall. Also, this model shows only minor relaxation in the hanging walls. The IUCM model was able to accurately predict the response of the rock mass in the hanging wall, foot wall and within the rib pillar.

An important point to note here is the degree of error that could have been made if the elastic and the SSMC models were used for assessment of the standoff distances for the key infrastructure. 


\section{Conclusion}

The selection of a suitable material model and modelling method is as important as the selection of appropriate input parameters in a numerical model. The conventional material models, and those employed by specialist modelling consultants, have a number of limitations that makes their application debatable. Some key limitations of these models, depending on the applied model, are:

- Elastic and SSMC models are not able to recreate all the complex physical/mechanical mechanisms that take place during the rock failure. Therefore these models lose their reliability as the level of complexity in the rock mass increases.

- There is no standard and consistent guideline for selection of input parameters when using the SSMC model, and this often leads to considerable inconsistencies between results generated by various practitioners.

- There is very limited transparency regarding the technical details and theoretical background of the proprietary models. These models are not available in the public domain and therefore cannot be critically reviewed by others. These models are mostly examples of black box systems where there is no knowledge of their internal processes.

- There is limited or no documented information highlighting the limitations and weaknesses of all of the above models.

The IUCM was developed with the intention to address the limitations of the current modelling practices. The IUCM gathers the most notable and widely accepted previous research work in the area of rock mechanics and integrates it into a unified constitutive model that can better and more accurately predict the stress-strain relationships in a continuum model. Several back-analyses and validation studies completed during the development of this model confirmed its applicability for a broad range of ground conditions, from intact brittle hard rock to heavily jointed and ductile rock, and also anisotropic rock.

In developing this model, the use of any new theory or technique was avoided where possible, and all the adopted processes were based on well-accepted and widely applied rock mechanics techniques and theories.

General features and benefits of the IUCM are:

- A detailed and transparent description of all the model's components are presented by Vakili (2016). This includes step by step instructions on the procedures that were implemented in each of the model's algorithms.

- The model has been extensively validated using several well-documented and well-known mining case histories.

- A detailed guideline for selection of input parameters is provided by Vakili (2016).

- A full description of the current known limitations of the model is provided.

- The IUCM can result in considerably more reliable modelling outcomes in more complex ground conditions.

- The IUCM only requires four compulsory input parameters for isotropic rocks and three additional input for anisotropic rocks. All these inputs can be obtained from conventional laboratory testing and rock mass characterisation, which are often available in most mining projects.

- Application of the IUCM requires much less expertise than other inelastic models. 


\section{References}

Alejano, LR \& Alonso, E 2005, 'Considerations of the dilatancy angle in rocks and rock masses', International Journal of Rock Mechanics and Mining Sciences, vol. 42, no. 4, pp. 481-507.

Andrieux, PP, Brummer RK, Li, H \& O'Connor, CP 2007 'Elastic versus inelastic numerical modelling of deep and highly stressed mining fronts', in Y Potvin (ed.), Proceedings of the Fourth International Seminar on Deep and High Stress Mining, Australian Centre for Geomechanics, Perth, pp. 51-57.

Barton, N 2013, 'Shear strength criteria for rock, rock joints, rockfill and rock masses: Problems and some solutions', Journal of Rock Mechanics and Geotechnical Engineering, vol. 5, no. 4, pp. 249-261.

Barton, N \& Pandey, SK 2011, 'Numerical modelling of two stoping methods in two Indian mines using degradation of c and mobilisation of $\phi$ based on Q-parameters', International Journal of Rock Mechanics and Mining Sciences, vol. 48, no. 7, pp. 1095-1112.

Brown, ET 2008, 'Estimating the mechanical properties of rock masses', in Y Potvin, J Carter, A Dyskin \& R Jeffery (eds), Proceedings of the 1st Southern Hemisphere International Rock Mechanics Symposium, vol. 1, Australian Centre for Geomechanics, Perth, pp. 3-21.

Diederichs, MS 1999, Instability of Hard Rockmasses: The Role of Tensile Damage and Relaxation, PhD thesis, University of Waterloo, Waterloo.

Diederichs MS, Kaiser PK, Eberhardt, E 2004, 'Damage initiation and propagation in hard rock during tunnelling and the influence of near-face stress rotation', International Journal of Rock Mechanics and Mining Sciences, vol. 41, no. 5, pp. 785-812.

Hajiabdolmajid, V, Kaiser, PK \& Martin, CD 2002, 'Modelling brittle failure of rock', International Journal of Rock Mechanics and Mining Sciences, vol. 39, no. 6, pp. 731-741.

Lorig, L \& Varona, P 2013, 'Guidelines for numerical modelling of rock support for mines', in Y Potvin \& B Brady (eds), Proceedings of the Seventh International Symposium on Ground Support in Mining and Underground Construction, Australian Centre for Geomechanics, Perth, pp. 81-105.

Martin, CD 1997, 'The effect of cohesion loss and stress path on brittle rock strength', Canadian Geotechnical Journal, vol. 34, no. 5, pp. 698-725.

Martin, CD, Kaiser, PK \& McCreath, DR 1999, 'Hoek-Brown parameters for predicting the depth of brittle failure around tunnels', Canadian Geotechnical Journal, vol. 36, no. 1, pp. 136-151.

Read, RS 1994, Interpreting Excavation-induced Displacements Around A Tunnel in Highly Stressed Granite, PhD thesis, University of Manitoba, Manitoba, pp. 328.

Vakili, A 2016, 'An improved unified constitutive model for rock material and guidelines for its application in numerical modelling', Computers and Geotechnics, vol. 80, pp. 261-282.

Vakili, A, Albrecht, J \& Sandy, M 2014, 'Rock strength anisotropy and its importance in underground geotechnical design', Proceedings of the Third Australasian Ground Control in Mining Conference, The Australasian Institute of Mining and Metallurgy, Melbourne, Carlton South, pp. 167-180.

Vakili, A, Sandy, M \& Albrecht, J 2012, 'Interpretation of non-linear numerical models in geomechanics-a case study in the application of numerical modelling for raise bored shaft design in a highly stressed and foliated rock mass', Proceedings of the 6th International Conference and Exhibition on Mass Mining, Canadian Institute of Mining, Metallurgy and Petroleum, Sudbury. 